\title{
18 \\ THE SCREEN AND THE WORLD: A PHENOMENOLOGICAL INVESTIGATION INTO SCREENS AND OUR ENGAGEMENT IN THE WORLD
}

\author{
Lucas D. Introna \\ London School of Economics and Political Science \\ United Kingdom
}

\author{
Fernando M. Ilharco \\ London School of Economics and Political Science \\ United Kingdom
}

\begin{abstract}
In this paper, we attempt to show how phenomenology can provide an interesting and novel basis for thinking about screens in a world where screens now pervade all aspects of our daily existence. We first provide a discussion of the key phenomenological concepts. This is followed by its application to the phenomenon of a screen. In our phenomenology of the screen, we aim to give an essential account of a screen, as a screen, in its very screen-ness. We follow Heidegger's argument that the screen will only show itself as a screen in its functioning as a screen in the world where screens are what they are. We claim, and aim to show, that our analysis provides many insights about the screen-ness of screens that we can not gain through any other method of investigation. We also show that although our method is not empirical its results have many important implications for the empirical world.
\end{abstract}


Keywords: Phenomenology, theoretical investigation, information technology, information systems, personal computer, television, screen.

\section{Introduction}

Whether at home relaxing with the family, or at the workplace, or traveling, or engaged in entertainment, a growing majority of people find themselves increasingly in front of screens - television (TV) screens or personal computer (PC) screens in particular.

The last decades have witnessed a massive penetration of TV screens into people's day to day lives. It is a long way from November 1937, when the BBC made its first outside broadcast - the coronation of King George VI from Hyde Park Corner - which was seen by several thousand viewers, to the landing on the Moon in 1969, carried by satellite to an estimated audience of more than 100 million viewers (Encyclopaedia Britannica 1999), and to the funeral of Princess Diana in August 1997, followed by an estimated TV audience of 2.5 billion (ABCnews 1999), which represents more than 40 per cent of the world's population.

The PC screen seems to be experiencing an even more accelerated spreading. By 1985 , there were 90.1 and 36.4 computers per 1,000 people, respectively in the USA and in the UK. Today those figures are around 580 and 441. From 1985 to 2000, that same figure for the whole of Europe went from 14.3 to 248.9, and for the world as a whole it went from 7.8 to 90.3 (Computer Industry Almanac 1999).

Although this phenomenon of the spreading of screens-TV and PC screens in this case - seems to have acquired a pervasive presence in the Western world, this pattern of spreading and implicitly colonizing the everyday world is no less significant in other cultures and in other regions of the world. In this paper, we want to inquire into the significance of our increasing engagement with screens for our understanding of ourselves and the world we live in. We contend that a suitable response to this question could in part rely on that which a screen is, qua screen. In this paper, we hope to demonstrate that the phenomenological method of investigation may be an appropriate way to proceed with such an inquiry.

\section{Part I: An Introduction to Phenomenology}

Phenomenology in the form of the phenomenological method of investigation is currently used in a wide range of fields, such as anthropology, sociology, psychiatry, biology, and so forth. Yet, we have seen very little of it in the field of information systems research (Boland 1978, 1983, 1985, 1989, 1991; Ciborra 1997; Introna 1997, 1993; Winograd and Flores 1987; Zuboff 1988). Even these studies to a lesser or greater degree use it only marginally or together with other approaches.

In this paper, we will attempt to demonstrate the possibilities of phenomenology in its original form as developed by Edmund Husserl (1859-1938). We will, however, extend the Husserlian formulation in the last phase of the method by using the arguments of Heidegger (1889-1976) (1962) on the opening up of concealed meanings, as proposed by Spiegelberg $(1975,1994)$. 
Phenomenology as a movement began to take shape a century ago with the impact of the first works of Edmund Husserl. ${ }^{1}$ This is in spite of the fact that both the word "phenomenology" and the intellectual activity it addresses were much older. Phenomenology "has long been on the way, and its adherents have discovered it in every quarter, certainly in Hegel and Kierkegaard, but equally in Marx, Nietzsche and Freud" (Merleau-Ponty 1962, p. viii).

The word phenomenology, which taken literally means the study or description of phenomena, has its origins in ancient Greek. Heidegger in Being and Time (1962, pp. 5063) traced back the meaning of the two components of the word phenomenologyphenomenon and logos - suggesting the following preliminary conception of phenomenology: "To let that which shows itself be seen from itself in the very way in which it shows itself from itself' (Heidegger 1962, p. 58). For Heidegger, this formulation does not say more than the well-known maxim of phenomenology "to the things themselves!"' Heidegger concludes phenomenology does not designate its own subject-matter: "the word merely informs us on the 'how' with which what is to be treated in this science, gets exhibited and handled" (Heidegger 1962, p. 59). This means that phenomenology is first and foremostly a method of investigation.

Its object is the way in which phenomena are treated, "such a way that everything about them which is up for discussion must be treated by exhibiting it directly and demonstrating it directly" (Heidegger 1962, p. 59). This directness is reached by the phenomenological method, which addresses the phenomenon as it is in itself for itself -in terms of its "thinghood" (Heidegger 1962, p. 59). This thinghood is the "beingness" or "is-ness" of a being, the "humanness" of humans, the "threeness" of three, and the "screenness" of the screen. This is-ness is the phenomenon phenomenology seeks to address - in its own terms.

\subsection{Some Key Concepts of Phenomenology}

For Husserl, the rigor of phenomenology was not that of exact sciences. "Scientific rigor was primarily the rigor of the deductive sciences familiar to the mathematician rather than that of the inductive natural sciences" (Spiegelberg 1994, p. 72). ${ }^{3}$ This rigor rather means that the foundations of knowledge must be absolutely primary and self-evident

\footnotetext{
${ }^{1}$ The Concept of Number (1887), Logical Investigations, Volume 1 (1901), and The Idea of Phenomenology (1906).

2"To the things themselves!" became phenomenology's watchword, stressed by all major phenomenologists, namely Edmund Husserl, Martin Heidegger, Maurice Merleau-Ponty (1907-1961), and Jean-Paul Sarte (1905-1980).

${ }^{3}$ Husserl, inaugural lecture at Freiburg in 1917: "We often speak in a general, and intelligible, way of pure mathematics, pure arithmetic, pure geometry, pure kinematics, etc. These we contrast, as a priori sciences, to sciences, such as the natural sciences, based on experience and induction. Sciences that are pure in this sense, a priori sciences, are pure of any assertion about empirical actuality. Intrinsically, they purport to be concerned with the ideally possible and the pure laws thereof rather than with actualities. In contrast to them, empirical sciences are sciences of the de facto actual, which is given as such through experience. Now, just as pure analysis does not treat of actual things and their de facto magnitudes but investigates instead the essential laws pertaining to the essence of any possible quantity, or just as pure geometry is bound to shapes observed in actual experience but instead inquires into possible shapes and their possible transformations, constructing ad libitum in pure geometric fantasy, and establishes their essential laws, in precisely the same way pure phenomenology proposes to investigate the realm of pure consciousness and its phenomena not as de facto exists but as pure possibilities with their pure laws" (in McCormick 1981).
} 
(apodictic). So, where are these "roots" of knowledge, these "pure laws," to be found? Husserl's first answer was in the things themselves, in the phenomena "in which all our concepts are ultimately grounded" (Spiegelberg 1994, p. 77). However, this was soon supplemented by another turn - a turn towards the subject. Husserl noted that a thing is always a thing for someone, thus, consciousness is the realm where things appear as that which they are in themselves, the real to be investigated.

To be conscious means to be conscious of something, i.e., to be directed toward something. Experience "always refer to something beyond itself, and therefore cannot be characterized independently of this...no straightforward sense can be given to an outer, external, world of objects which are not the objects of such experiences" (Hammond, Howarth, and Keat 1991, pp. 2-3). Intentionality means nothing more than this property of consciousness of being always already conscious. Because to be conscious is always to be conscious of something, intentionality is the consciousness as directed at something. Intentionality, addressed in this way, as structural to consciousness, is the ground from where phenomenological analysis proceeds.

That which appears in consciousness is that which is to be addressed without taking an a priori stand on its empirical existence or non-existence. For example when one identifies a particular object as a screen, the screen-ness of screen must already be present in subject's consciousness, otherwise this identification would not be possible. Phenomenology deals with this essence implied in the act of intentionality as such, i.e., it addresses this implied what-is-ness, in contrast with empirical existence of that addressed in such identification - which is rather a matter of this-ness or there-ness. For irrespective of its source - be it mental or sensory - "behind" every judgement about the particular there always already exits an essence that made such judgement possible in the first place.

Phenomenology has its object prior to the grounds of the empirical existence of a particular phenomenon, aiming at a pure description of it before any judgement about its existence can be made. Thus, the objective of phenomenology is to describe phenomena as they are in human consciousness - "the real has to be described, not constructed or formed" (Merleau-Ponty 1962, p. x). Phenomena are to be described faithfully and without presupposition, that is, as they primarily appear in consciousness, stripped out of historical contexts, scientific explanations, and philosophical interpretations-without presuppositions, free from prejudices, that is, not pre-judged.

Because phenomena in consciousness is the theme of phenomenology, and not their existence or non existence, the insistence on the presupposition of the world as empirically existent-as a condition for knowing - must itself be suspended. The existence of the world must be put between brackets, not because the philosopher should doubt it, but merely because its existence is not the theme of phenomenology as such (Biemel 1980, p. 627). The concept of "reduction," or "epoché," means this suspension of belief in the empirical existence of the world as the ultimate condition for its knowing. That which is to be apprehended is the pure phenomenon in consciousness, dropping all reference to the individual and to its particularities, as it manifests itself in consciousness, without any kind of evaluation, such as real, unreal, existent, non-existent, imaginary, etc. Reduction suspends the assumptions of the natural attitude, that is, suspends the takenfor-granted, everyday existence of the world, and returns to the things, as they are experienced in consciousness. 
When we face an object, a situation, or an idea and "bracket" out its empirical existence and then describe it, we obtain an example. This description of the example is not yet the essence of the phenomenon, but it is a first reduction ${ }^{4}$ toward the core concept of essence. But what is an essence for phenomenology?

Phenomenology studies essences (Heidegger 1962, 1977, 1978; Husserl 1960, 1964, 1970b; Merleau-Ponty 1962). The traditional signification of the word essence means what something really is (in its own terms). When addressing that which makes a thing "is" what it is, we do not take into account those particulars that makes a thing a specific thing in time and space - a concrete empirical object: Rather, we focus our attention on those elements necessary for something to be part of a class of things we already take it as belonging to. When distinguishing something particular, identifying some concrete object, or characterizing some specific event, we implicitly admit to know in advance the kind of thingness to which the thing we are talking about belongs.

This initial meaning of the word essence has the character of an a priori necessity, a non-empirical, universal, and unconditionally valid condition (Husserl 1970b). However, we should point out that the concept of essence underwent some change in the work of Heidegger. He did not understand it simply as "what something is," but also as "the way in which something pursues its course, the way in which it remains through time as what it is" (Lovitt in Heidegger 1977, footnote 3). Heidegger re-addressed the issue of essence versus existence under the more fundamental question of the meaning of Being. The "what-Being" (essence) and the "that-Being" (existence) are undercut by the opening up of Dasein's essence "in its existence" (Heidegger 1962, p. 67). Thus, Heidegger tried "to develop a non-traditional concept of essence as "essential unfolding" (wesen as a verb)" (Polt 1999, p. 64). ${ }^{5}$ It is this temporalized notion of essence that we would also adopt for our investigation.

Let's consider as an example a computer screen. Why is it that we are able to refer to a particular screen as a screen? To recognize particular screens as particulars implies to recognize that those screens are particulars of something else. Screens as particular must be delimited, actualized, concretized, specified, that is, they go beyond something that is common to all of them. This something common to all of them is that which is not particular but universal, i.e., that in which the essence of a screen is to be found. Thus, whenever we identify a thing as a particular thing (object, experience, event, and so forth) we have in fact unknowingly already entered the ground of essence.

Contrary to what a common understanding of the word essence suggests, to arrive at the phenomenological concept of essence, we can not rely on empirical generalization, comparing many examples and identifying the common features they have. This is so, mainly, for two reasons. First, the actualization of an essence in a particular context means an understanding in real terms that may add various non-essential elements because it happens within the domain of empirical existence. Second, what is common

\footnotetext{
${ }^{4}$ Husserl defended the reduction as a first step of a phenomenological investigation: only after the existence of the world has been bracketed should we proceed describing the phenomenon (Husserl 1960, section 20). This clearly made sense in his investigation into consciousness, the Ego, as it is. However, when ones investigates phenomena in the world it seems more advantageous to perform the reduction only as a second step, that is, only after a first description of the phenomenon has been done.

${ }^{5}$ This remark from Polt suggests the use of the English word essence as a verb: as to essentiate.
} 
to any given quantity of examples is not necessarily the essence of the examples. The essence, of course common to all the examples, is common not only to the examples analyzed but also to every potential example of that phenomenon. This is so because the essence is such that without it there is no phenomenon.

Furthermore, the process of generalization itself already presupposes the existence of essence since

the abstraction of the general idea "red" is arrived at by leaving out of account all those respects in which several red objects differ in order to hold on to that respect in which they are similar. But the concept of similarity (or even respect) which is in question here itself presupposes the very comprehension (of the essence of "red") which it is supposed to account for [Macann 1993, p. 9]

Therefore, essences are not generalizations. They are a different kind of common features inasmuch as they are the decisive elements in every particular example, whose actualization implies these decisive elements of the phenomenon in question. Essences are not actualized as something here or something there, because they do not exist in the actual world, but are in the very structure of consciousness, as foundations of knowledge and experience - as a priori and necessary features for knowledge and experience, as is clear in the case of generalization central to the empirical science.

The idea of a screen, against and in which all actual screens are confronted, is the original object, and does not necessarily follow from existence in any real world outside consciousness; it only remains as the necessary substrate for an object to be that which we designate it to be. This ideal object, intuited as it were, is the essence of all the actual objects we distinguish as part of a class, which is precisely defined by that same essence.

With these key concepts in mind, let us now turn to a discussion of the phenomenological method of investigation.

\subsection{The Phenomenological Method of Investigation}

Phenomenology is primarily a method of investigation. It is not a philosophical answer in itself but rather a way of questioning. As Heidegger (1977) wrote, this questioning builds a way, and this way is a way of thinking. The foundational basis of this thinking, of the method, is evidence and logic. Evidence here must not be confused with evidence in the empirical sense. Here evidence is that which is evident in itself, that which is impossible to conceive otherwise. In other words, to deny it would be to deny the very source of any empirical judgement already presumed. To ensure this interpretation we will use the term "self-evidence" but with this particular meaning in mind.

Only because consciousness is already evident for itself can consciousness logically conclude its own evidence. And it concludes logically because logic is the understanding in which consciousness is as such. Thus, for Husserl, evidence and logic are the indisputable grounds of thinking. Evidence and logic are in themselves self-evident, absolute primary, only relying on themselves to appear as themselves in the ways they are in themselves, that is, as necessary truths. 
Like any other method, the phenomenological method of investigation is realized through a methodological circle; however, phenomenology strives to accept and to proceed only within the primary and foundational circle of human understanding: consciousness and it's a priori rules and procedures.

When applying the phenomenological method to uncover the essential nature, the isness, of the screen, we will closely follow the phenomenological method as it was synthesized by Spiegelberg $(1975,1994){ }^{6}$ Nevertheless we felt that minor changes were needed on the basis of our ontological and epistemological assumptions, laid open as the investigation proceeds, and on the basis of the nature of the phenomenon revealed by analysis. In so doing, we consider the traditional phenomenological investigation of the etymology of the words, which identify the phenomenon, not merely as a step of the first phase of the method but rather as a whole second phase in its own right. ${ }^{7}$ Such an adaptation is clearly supported by Heidegger's phenomenological investigations (Heidegger 1962, 1977, 1978).

Thus, the phenomenological method we will apply in our investigation has the following phases:

(1) Describing a particular phenomenon

(2) Analyzing the etymology

(3) Performing the phenomenological reduction

(4) Investigating essences

(5) Apprehending essential relationships

(6) Watching modes of appearing

(7) Interpreting concealed meanings

These seven phases constitute our full phenomenological method of investigation as Husserl developed it and as it was to a large extent synthesized by Spiegelberg (1975, 1994). In specifying these seven sequential phases, as we use them in this research, we want to stress their implicit union and their essential connections. The phases are united in the basic purpose of "giving us a fuller and deeper grasp" (Spiegelberg 1975, p. 57) of the phenomenon, which can only be achieved once all the seven phases were fully applied. Let us very briefly characterize each of the seven phases of the method with reference to our analysis of the screen. ${ }^{8}$

\footnotetext{
${ }^{6}$ Encyclopaedia Britannica (Biemel 1980, p. 630) classifies Spiegelberg's The Phenomenological Movement-A Historical Introduction (1994) as the "movement's first encompassing historical presentation." That work is an essential text both on the history of the movement, and on the technical issues pertaining to its method as well.

${ }^{7}$ For the same reasons, we decided not to separate the analysis of "the constitution of the phenomenon in consciousness" as a single phase, but to include it within the investigations of the fifth and of the sixth phases of our method-Apprehending Essential Relationships and Watching Modes of Appearing, respectively - as it revealed to be more insightful.

${ }^{8}$ Unfortunately, due to space limitations, we can not provide a detailed discussion here. We hope that the analysis of the screen will make the method clear. Also refer to Spiegelberg's account for more detail.
} 
- Describing a Particular Phenomenon. This phase aims at a returning to the world as primarily and directly experienced, setting up the horizon of the phenomenon screen as "free as possible from presuppositions" and as intuitive as possible.

- Analyzing the Etymology. The task here is to trace back the origins of the words identifying the phenomenon screen. This analysis of the words is not destined to bring back the meaning of words, but rather to bring forth the meaning of the things themselves in the ante-predicative life of consciousness.

- Performing the Phenomenological Reduction. To perform upon the description of the first phase the reduction, bracketing out the features concerning the actuality - the particular presence in time and space - of any given screen. The phenomenon is reduced to a phenomenon in consciousness.

- Investigating Essences. This phase aims at reaching the elements strictly necessary for the phenomenon to be what it is. First, through generalization, the common features of screens are identified. Second, freely varying in imagination these common features, we strip them out of those elements that, despite being common, are not necessary, thus, leaving us the essence of the phenomenon screen.

- Apprehending Essential Relationships. This phase is an attempt to refine the essence of screen through a priori insight based on logic operations, which are to be performed within the essence of screen, and in what concerns its relationships with closely related phenomena. This aspect will be clearer when trying to relate the phenomenon screen with the ideas of data and world.

- Watching Modes of Appearing. The phenomenon screen is now to be investigated precisely in what concerns its appearances. Having identified the essence of screen, now the task is to pay attention to the ways in which such phenomenon appear: the aspects, contexts, perspectives, and modes in which it shows itself.

- Interpreting Concealed Meanings. This last phase of the phenomenological method, introduced by Heidegger (1962), is provided to give access to phenomena whose essence, whose meaning, has in itself concealment. We will show it to be particularly relevant for the case of the phenomenon screen. This phase involves decisive ontological and epistemological claims because that which is given in the phenomenological analysis is taken into account in the analysis of that which is doing that same analysis, and so on in circular movements. ${ }^{9}$

In Part, II we will apply the phenomenological method to uncover and explore the essence of the screen. The analysis will proceed carefully by following the phases outlined above. Due to the nature of the method there will by necessity be some repetition of formulations and reconsideration of statements and positions previously taken.

\footnotetext{
${ }^{9}$ To fully appreciate the method, we will make explicit core ontological and epistemological assumptions and this, in its turn, will enable us to bring forth concealed but relevant meanings of the phenomenon screen.
} 


\section{Part II: The Screen}

\subsection{Phenomenology of the Screen}

A major part of our lives is becoming places located in front of screens. Is this significant for our understanding of ourselves and the world? We believe our phenomenological analysis will provide some insights into this question.

When phenomenologically investigating the screen, what we intend to think is not the content of television as such, or the kind of data we work with while facing a PC screen, but rather the screen as itself, in its screen-ness. It is the screen as a content of a specific understanding of the world and as a part, an enabler, or an element, of a concrete way of relating ourselves to and in the world that is the focus of our investigation.

\subsubsection{Describing the Phenomenon Screen}

From the start it is rather surprising what we encounter when starting the phenomenological analysis of the screen. When trying to describe a screen, a computer screen or a television screen, we immediately note that we never seem to look at a screen as a screen. We rather tend to look at screens in watching what appears on the screen. What seems evident when looking at a screen is the data presented on that screen-the text, images, colors, graphics, and so on-not the screen itself.

To try and look at a screen, and see it as a screen, not taking into account the particular data it presents, is apparently not an easy task. We are not familiar with this type of encounter with a screen. Rather our familiarity with screens are things-maybe surfaces - that function in particular contexts and for particular purposes, that is to say, we use screens as we act and relate ourselves to and in the world. This familiarization does not mean we consciously know what a screen is. Rather, that we are accustomed to screens, that is, we are accustomed in our daily life to perform the kind of activities in which screens are a part, are elements, participate in, or are present as just naturally "there." With Nietzsche, we note that "the familiar is that to which we are accustomed; and that to which we are accustomed is hardest to 'know,' that is to see as a problem, that is to see as strange, as distant, as 'outside us"' (1974, No. 355, p. 301).

However, in our phenomenological investigation, we take note to recover this strangeness - that is, that we seem not to see screens qua screens. Nevertheless, this strangeness is not the strangeness of a turned off screen, its strangeness is rather revealed in that we note its presence as a mere object, a piece of the furniture as it were. It might be this strangeness that often moves us to turn on the television or the computer screens we face. It is only when we look at the screen phenomenologically, as screen, trying to focus on itself as screen - but not as a turned off screen - that we enter the grounds of the screen as an "intentional object" of consciousness. What do we note?

Screens present, show, exhibit what is supposed to be the relevant data in each context, be it a movie while watching TV, a spreadsheet while working at the office, or a schedule while walking in the airport. Screens exhibit what was previously captured, processed, organized, structured, and finally presented on the screen. But what do we mean by "presented on the screen"? What is this "presented"? What is the data in question? Who presents it? Whom, where, and why? 
The screen, as a screen, always finds itself at the center of the activity: in showing it attracts our attention, often also our physical presence, as it locates our activity. It is often the focus of our concerns in that environment, being at the office, working, or at home, watching a movie or the news. A screen gathers the attention of the people that surround it. Actions of those people are usually directly shaped by the presence of the turned on screen, by the kind of data it presents and by the understanding people surrounding implicitly assume of that data, which generates particular comportment and attitudes. ${ }^{10}$

So far the description of a screen is leading us into the notions of showing relevant data for and about each particular situation, of getting attention, of suggesting relevance, of acting as a mediation between ourselves and the world, and of gathering that which is appropriate in each particular context. We now have a first description of the screen. It is worth noting at this point that, although we do have a number of other words for screens such as display, output device, cathode ray tube, liquid crystal display, flat panel display, display window, and so forth, nevertheless, when engaged in everyday practices around them we tend to refer to them as screens.

We will now expand our investigation by an etymological analysis of the word screen, trying to uncover in this manner its meaning, and juxtaposing it with the description already presented.

\subsubsection{Analyzing the Etymology of the Word Screen}

Screen looks like a rather simple word. It is both a noun and a verb and its contemporary plurality of meanings can be collected along three main themes: projecting/showing (TV screen), hiding/protecting (fireplace screen), and testing/selecting (screening the candidates) (The Oxford Paperback Dictionary \& Thesaurus ${ }^{11}$ 1997, pp. 681-682).

The origins of the word screen go back to the $14^{\text {th }}$ century. According to the WWWebster Dictionary ${ }^{12}$ (1999), the contemporary English word screen evolved from the Middle English word "screne," from the Middle French "escren," and from the Middle Dutch "scherm." It is a word akin to the Old High German (eighth century) words "skirm," which meant shield, and "skrank," which meant a "barrier" of some kind.

The word screen still suggests another interesting signification, further away from us in history. It is a word "probably akin" (WB) to the Sanskrit (1000 BC) ${ }^{13}$ words "carman," which meant skin, and "krAnti," which signifies "he injures." These meanings, possibly, are the ones from which the Middle Age words evolved. The Sanskrit origins

\footnotetext{
${ }^{10}$ Screens only function as screens when turned on. If a screen is turned off, it is just an object in the background. The screen comes to the foreground only when we attend to it for turning it on. When we push the on button, the screen locates our attention, we sit down, quit other activities we may have been performing, and watch the screen, as it is the place, the location, where that which is relevant for us in that particular time is to happen.

${ }^{11}$ From now on quoted as OPDT.

${ }^{12}$ From now on quoted as WB.

${ }^{13}$ Sanskrit-the language in which "The Vedas," the oldest sacred texts, are written-was an early form of an Indo-Aryan language, dating from around 1000 BC. The Indo-Aryan languages derived from Proto-IndoEuropean (before $3000 \mathrm{BC}$ ), from which also evolved Slavic, Baltic, Classical Greek, Latin, Germanic, and other families of languages. Old High German, Middle English, and Middle Dutch, belong to the West branch of the Germanic family. Middle French belongs to the Italic (Latin) family (Crystal 1987).
} 
suggest that the notions of protection, shield, barrier, separation, arose as metaphors of the concept of skin, possibly of human (or animal) skin.

We should say that for our analysis none these meanings of the word screen has a definitive superiority. What is decisive is that the tracing back of the evolution of the meaning of the word screen enables us to penetrate the realm in which the word had its origins and in which it has evolved:

What counts, rather, is for us, in reliance on the early meaning of a word and its changes, to catch sight of the realm pertaining to the matter in question into which the word speaks. What counts is to ponder that essential realm as the one in which the matter named through the word moves. [Heidegger 1977, p. 159]

The etymological analysis performed so far indicates that the word screen moved from Sanskrit meaning of skin and injury, along protecting, sheltering and covering, to the modern day projecting, showing, revealing, as well as electing, detecting, and testing. Now we may ask the following: Is there any central intent, distinction, or feature, common to all these specific meanings of the word screen? We believe the answer is yes. To defend such an assertion we will take up a different but related route, that of sound analysis.

The word "screen" is pronounced "skri:n."14 It is close in its sound to the word "scream," pronounced "skri:m." It is just a final sound that distinguishes both words. The core sound of both words is the same. Do they both point to something beyond themselves?

The correspondence between sounds and meanings remains to a great extent an enigma. In spite of several attempts having been made to find specific accords between sounds and meanings, there is only "limited evidence on a few broad sound/meaning correspondences in language" (Crystal 1987, p. 175). However this state of affairs does not mean that this kind of sound analysis is senseless. Quite the contrary, that in some cases "speakers feel [that certain forms in language] do have a close relationship to objects or states in the outside world [means that] individual sounds are thought to reflect, or symbolize, properties of the world, and thus to 'have meaning'" (Crystal 1987, p. 174). ${ }^{15}$

When we look carefully at both of these words in the English and the Portuguese languages we can discern some interesting insights. The Portuguese word for screen is "écrã" (pronounced "Ekrã"), and for scream is "grito" (pronounced "gri'tu"). Quite different words at a first glance. However these two Portuguese words, as it is the case for the two English words referred above, have a common core sound. "kr" and "gr" are the same sound but for a very minor variation - the sound "gr" is almost the same of the sound "kr," only with a not so stressed "k"16 (refer to Figure 1).

\footnotetext{
${ }^{14} \mathrm{We}$ will use the standard International Phonetic Alphabet (IPA) in the sound analyhsis.

${ }^{15}$ Onomatopoeia is the most striking example, but other cases have also been researched as well (Crystall 1987, pp. 174-175).

${ }^{16}$ In Portuguese, it is possible to pronounce "grito" as "kri:'tu" without being misunderstood or incurring a worth mentioning mistake.
} 


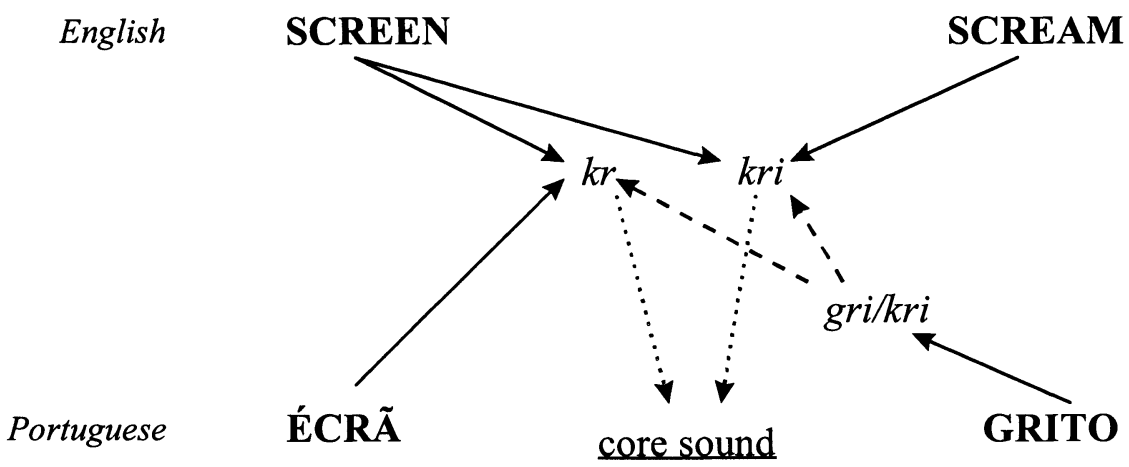

Figure 1. Sound Analysis of Screen and Scream

Thus, the question one needs to consider is if there is any meaning attached to the core sound "kr/kri"? By now, taking into account the analysis so far performed on screen, and the common meaning of scream, the answer appears intuitively: "to call for attention." "To call for attention" seems to be the meaning attached to the sound "kr/kri" for both words in both languages. A further scrutiny of the sounds in question strengthens such a conclusion.

The Portuguese word "écrã," a quite recent word, is clearly similar to the Middle French word "escren," referred to above. The corresponding current French word is "écran." 17 Is it the case that this initial "e," which the word screen does not have, has any specific meaning?

At a first glance the meaning of the " $\mathrm{e}$ " may seem a worthless question as it is a widely recognized principle of phonetic "that individual sounds do not have meaning: it does not make sense to ask what "p" or "a" [or "e"] mean" (Crystal 1987, p. 174). However, we must recall that we are not interested in words or in letters de per si, but rather on the things or concepts to which they refer.

Before continuing our analysis is important to note that although this kind of phenomenological analysis does share some concerns with linguistic analysis, it goes beyond it. This analysis is not destined to bring back the historical original meaning of those words, but rather to bring forth the meaning of the thing itself, around which the acts of naming and expression took shape" (Merleau-Ponty 1962, p. xv). What is at stake here is the bringing back of all the relationships implied in our experiencing of the phenomenon, the screen in this case. In the analysis of sounds, we intended to uncover or bring back some of the intentionalities implied in the way the words functioned. This is the reason for moving beyond the words, as words, to their sounds.

\footnotetext{
${ }^{17}$ Usually the Portuguese word for screen is “écrã," in Dicionário Universal da Língua Portuguesa (1999). Some other dictionaries write it exactly as in French, "écran" (Minidicionário Verbo-Oxford de Inglês 1996). Still others do not include it at all, for example Dicionário da Língua Portuguesa (1989). The Portuguese word is an appropriation of the present French word "écran" that evolves from the Middle French word "escren." Both Portuguese and French evolved from the Italic (Latin) languages.
} 
The "e" we are addressing has the sound "e." So the appropriate question is: What does this " $e$ " sound mean? The answer is a surprising one. The letter " $e$," that represents the sound in question, is widely used in Portuguese as a prefix. ${ }^{18}$ Yet, as we further inquire into the sound " $\mathrm{e}$ " we note there is indeed a Portuguese word that only has that sound: the word "eh!" (Dicionário da Lingua Portuguesa ${ }^{19} 1989$, p. 580). This word is a grammatical interjection, ${ }^{20} \mathrm{a}$ "designate of surprise, admiration, and calling"21 (DLP, p. 580; translation ours).

This word "eh!" is commonly used in the Portuguese language in situations where someone wants to call the attention of someone else. Let us consider an example and the respective English translation: "Eh! Anda cá" means in English "Hey! Come here." We evidently note that in both languages the first word "eh"/"hey" is pronounced, that is, is destined, to call the attention of the one we want to "come here." The English word "hey," the most common translation of the Portuguese word "eh" (Michaelis Illustrated Dictionary, Voume. I, English-Portuguese 1958, p. 502), means exactly "calling attention" (OPDT, p. 349).

If this is so, one may ask what about the word screen? Maybe the word screen never had an initial "e," because the English language, as it evolved from the Middle Ages to the present day, seems to have had other solutions to emphasize the meanings at stake: the sounds "scr" and "i."

The Middle English word for screen was "screne." Contrary to what happens in the Portuguese language, in English the sound "scr" seems to have been widely preserved up to the present day use. The sound "skri:," the common core sound of the words screen and scream, adds to the sound "scr" the sound " $\mathrm{i}$," which is precisely a key sound of the English word hey. This word, as with the French "hé" and the Portuguese "eh," means a calling for attention - but only the English word has the "i" sound. This sound " $i$ " seems to be the one that in the English word screen that takes the place of the sound " $\mathrm{e}$ " in the French and Portuguese words "écran" and "écrã," as they seem to have the same meaning.

Thus, we could conclude that from the Middle Ages to the present day, the evolution of the Middle French word "escren" and of the Middle English word "screne" followed the same path. Escren became écran, screne became screen, that is, in both evolutions, each according to its own context, the words moved toward stressing the "call for attention" intention implied in their usage.

The work done in this step leads to an idea that is in some important ways close to the one we had by the end of the previous step. This is the idea of screen as the bringing forth of (or calling forth for) attention and thereby implying relevance, since "calling attention to" always imply the supposition, correctly or incorrectly, of relevance. If the "attention" mentioned is our attention, to what does "relevance" refer? A first answer could be that relevance belongs to that presented on the screen (calling for our attention).

\footnotetext{
${ }^{18}$ It comes from the Latin and has the meaning of an outward movement (Dicionário da Lingua Portuguesa 1989, p. 574), which is in line with the meanings of projecting and showing that the word screen gained in Portuguese, in French, and in English.

${ }_{19}^{19}$ From now on quoted as DLP.

${ }^{20}$ It comes from the Latin word "ehe-" (DLP, p. 580).

${ }^{21}$ Its French translation is "he!" pronounced just in the same way, "“e" as well.
} 
If screen implies the calling for attention and such calling implies relevance, then we need to further analyze this implied relevance, as this seems to belong to the essence of screen. Is this relevance a matter of the content of that which is on the screen or does screen in its screen-ness (or screening) already presume it?

\subsubsection{Performing the Phenomenological Reduction on Screen}

At this point we must recall that, in order to reach the essence of screen, we should concentrate on the phenomenon screen as it appears in consciousness, not as thought, or as we assume it appears in an "outer empirical world." It is now important that we suspend belief in the existence of any particular empirical world, as a condition of our analysis. This is done by performing the phenomenological epoché. This means "reducing" the phenomenon screen to that which appears in consciousness, disregarding characteristics that value it as particular empirically "existent" things, while attempting to preserve its content as fully and as purely as possible. Nevertheless, this intentional object, the screen in consciousness, is not some pure isolated thing that has meaning in itself as such. It always claims to be, in its essence, a something in-the-world, not an isolated object in consciousness. Its being, as it appears in consciousness, is one of always already referring to its functioning in a world in which it makes sense, because it, and the other things and activities in the world, ${ }^{22}$ mutually refer to each other - what Heidegger calls the "referential whole" (Heidegger 1962).

Having suspended the supposition of existence in the empirical world, thus in the existence of particular empirical screens as well, we discover that in consciousness screens qua screens still seem to exhibit attraction as that which it is. Without "calling for attention," screens would no longer be screens, merely surfaces or objects. Screens, in their screen-ness, are promises of bringing to present what is relevant and, simultaneously they hide their claimed physical being behind that same data, only calling our attention to the showing as such.

Screens, as screens, function in our flow of involvement in the world. Because this data is presented within our flow of involvement it is already relevant data - that is, data deserving our attention. The reduced phenomenon of screen appears in consciousness as something devised to attract - or rather already have-our attention and locate our action as acting beings in the, even now "suspended," supposed existent world.

This last argument can be made more clear by experiencing the kind of difficulty one has to go through in order to imagine a situation in which screens do not present relevant data at all. For example, a PC monitor at NYSE showing on a permanent basis the schedule of the trains of the suburbs of some African city; or the monitor of the cash registers of a supermarket showing air traffic control data. They may have an initially curiosity value but will quickly become ornaments in the background. These cases demonstrate the difficulty of imaging these displays as screens because to do it we would

\footnotetext{
${ }^{22}$ Throughout the discussion, we use the notion of world in the Heideggerian sence as a significant whole in which we dwell. Refer to section III of Part One of Being and Time, to Polt (1999, pp. 49-59), and to Dreyfuss (1991, pp. 88-107).
} 
need to abandon the grounds of the essence of screen, and still force ourselves to use that same essence to understand an object that looks as having lost its screen-ness.

Screens display relevant data for us in each situation that engages us in the always supposed whole in which we relate ourselves. However, it is not the kind of data we immediately and intuitively grasp as human beings already in-the-world. ${ }^{23}$ Rather this data is produced in such as way that it only appears for us (grabs our attention) in our "involvement whole" (Heidegger 1962) in which it refers to our activities and our activities refer to it, within a particular "form of life" (Wittgenstein 1967). For example, we can imagine what a man from the $15^{\text {th }}$ century might think when confronted with a screen of an Automatic Teller Machine (ATM). That screen would be an object for him, but it would not be a screen because it would be impossible for him to conceive that particular screen in its screen-ness, i.e., in its essence. That screen would not be a screen for that man because that screen was not a screen for him-he would simply not recognize it in its screen-ness. Anything we do not recognize can be understood as many other things but for the thing that which it is.

Screens, in their screen-ness, claim a being in-the-world as focal interpretative surfaces, presenting relevant data for our involvement and action in the world. Screens promise to make evident our involvement in-the-world, because they present an already interpreted and reduced world to us, which is already consistent with our involvement in that world, our form-of-life.

This phenomenological reduced description of screen shows how closely intertwined are the ideas of attention, relevance, and world in the concept screen. However, this is not enough for a fully phenomenological characterization of the phenomenon screen. In order to reach the essence of a screen, we must now try to reach beyond the common elements to identify the strictly necessary elements for the phenomenon screen to be what it is.

\subsubsection{Investigating the Essence of Screen}

So far in our analysis we have relied on the general-ness of that which a screen is. However, this common-ness is not the essence of the phenomenon. We have already started to move beyond this commonness. As indicated before, essences are not generalizations. The essence of a screen is not that which is general to the screens so far addressed or to any screens that might be addressed. Essences are a different kind of common features inasmuch as they are the decisive elements in every particular example, whose actualization, in its turn, must imply existential elements of the phenomenon in question - thus, locating the example out of the domain of essences.

The essence, of course common to all the screens, is common not only to the examples analyzed but to all potential examples of that phenomenon, because the essence is such that without it there is no phenomenon. Thus, the essence can still rely on fewer elements than the common ones and suggest more than that which was revealed as common to the particular cases addressed. Imagination - "by discovering what one can and what one cannot imagine" (Hammond, Howarth, and Keat 1991, p. 76) - is the key

\footnotetext{
${ }^{23}$ Data on screens is not "natural information," according to Borgmann (1999, pp. 7-54).
} 
of the following analysis, aiming at stripping out of screen those elements that, in despite of being common, are not necessary for a screen to be a screen.

We do not need empirical observation for discovering the answers we need because in every new variation in imagination we know the object we describe is an object of that same kind, a screen, if we recognize it as such, as a screen. Thus, the implicit criteria of recognition-my ability to recognize the object as the object it is-is the decisive way of this essential (eidetic) reduction.

First, we note that the same surface can be considered a screen and not considered a screen even if it displays the same data, as is clear from our example of the ATM above. If we have a mirror, with the size and shape of a screen, it displays data-the images it reflects - but we do not consider it to be a screen but a mirror. Yet we can have a screen displaying exactly the same image of that mirror and consider it a screen and not a mirror. So, what is the criteria that is implicit in this imagined experience?

Mirrors reflect, screens (re)presents. ${ }^{24}$ This means the kind of data displayed by these different objects have diverse origins. In the case of a mirror, it is merely reflecting back what it receives. In presentation there operates a fundamental process of ordering. Presentation always assumes a theme - in the way that a jigsaw puzzle, to be a jigsaw puzzle, assumes a whole that will be its ordering criteria. Furthermore, the theme of the presentation assumes - or derives its meaning from - a form of life that renders it meaningful as a relevant presentation. As Wittgenstein argued, words do not refer to something because we agreed it; rather, they already have meaning because we share a form of life (Wittgenstein 1967, No. 241, p. 88). Thus, data presented on screens does not depend on the perceiving subject perspective but on the "themes" and "forms of life" in which it already functions as meaningful. Screens present selected data, that is, data that was previously selected to be displayed or data that is displayed because it is in accordance with a previously set theme for the presentation of data in that form of life. This last criteria means that the kind of data presented is the relevant data for the situation within the context where that screen makes sense being used as a screen. Screens always present relevant data-as themes in forms of life-and therefore gather and locate the attention of the people surrounding them.

Screens are not mirrors in that they do not reflect whatever they face. They present what is already relevant within the flow of purposeful action. The content/surface of screens is always already a presentation: the world made present according to a theme in a particular form of life. In watching, one could of course disagree with the relevance of the particular data being presented on the screen, but that evaluation itself is already relevant for the situation in which the viewer finds herself. ${ }^{25}$

We must also note that in selecting for presentation other possibilities are always implicitly excluded. Thus, the screen, as screen, "conceals" and "filters" in its revealing. This revealing/concealing attached to that which would be the phenomenon screen,

\footnotetext{
${ }^{24}$ In the discussion we will use the term presentation as it seems to us more effective in opening up the domains of meaning that we intuitively experience as relating ourselves to screens. However it will be technically more correct to use representation if we want to be consistent with Husserl's terminology. Refer to Husserl's The Phenomenology of Internal Time Consciousness.

${ }^{25}$ It may indeed be a crucial part of the context that precedes a relevant action of the subject; that is, a choice, a decision, a possibility for being, or even a stand on the grounds of meaning.
} 
initially addressed when analyzing the etymology of the word screen, seems to keep on emerging as that which is essential to screen-ness. Let is further reflect on this.

Heidegger (1977) noted when investigating the concept of truth that for the ancient Greeks the word for truth was aletheia, meaning the simultaneous revealing and concealing of something. A revealing must in itself include a concealing of that which was not revealed. Likewise a concealing must include a revealing of that which was not hidden. The one always includes the other unless we admit the possibility of an absolute revealing of everything under all perspectives in every term and in all contexts, which human understanding evidently denies. Thus, to reveal implies to conceal. However, it also implies more.

If something was indeed revealed - and something else likewise concealed - in the presentation, then this possibility brought about discloses a notion of an already there implicit agreement. We must emphasize that our discussion only refers to screens, qua screens, which collect and attract attention. Obviously this agreement does not mean that one has to necessarily agree with the terms, conditions, analysis, or format of that which is revealed. The agreement is only that that which is revealed-on the screen qua screen-is present as that which attracts our attention as part of our ongoing activity in that form of life.

Where has this inquiry lead us to thus far? The essence of screen is being constituted in gathering attention by the presentation of relevance (and the concealment of irrelevance) in order to mediate our being in the world. This is to say that because we are acting in the world, always already engaged with our attention focused on something, the essence of screen is the presentation of relevance to mediate and (re)constitute the world. We now consider it appropriate to suggest the following essential description of a screen: the essence of screen is to mediate our being in the world by presenting relevance in that world. This concept should be kept open for further scrutiny because the notion of relevance, although implying the idea of hidden-ness, does not allow it to be brought forth. We also need to give more careful consideration to the idea of agreement that is emerging.

\subsubsection{Apprehending Essential Relationships/Watching Modes of Appearing of Screen ${ }^{26}$}

A screen always presents data of/in the world, that is, a screen presents the world in that the world on the screen is always accessed as the perceived world of my ongoing flow of activity - for example, the screen of the ATM is the world of my ongoing economic activity, the screen at the airport is the world of my ongoing travel activity. Thus, an understanding of the idea of screen implies the idea of world, as well as the ideas of attention and relevance. The kind of data that is displayed is neither reflections nor random data, but data generated by specific and usually complex and time consuming criteria or themes conceived by us. Thus, this relevance is dependent on a previous understanding of our activity in the world. It seems that a structural understanding of

\footnotetext{
${ }^{26}$ We present the results of these two phases together as their findings are clearly related.
} 
screen implies at its essence the linkages between the ideas of presentation, relevance, and world-as noted before.

Can we now bring together the different stands of our analysis by rethinking our initial tentative concept of the essence of screen-a mediation of our being in the world by presenting relevance. Why does the screen in its essence not show invisibility, this hidden-ness, implicit in the presence of a screen? If the essence of a screen is to mediate our being in the world, that is, our activity in the world, by presenting relevance, why does the screen make itself invisible, that is, not relevant? Why in the essence of screen does this invisibility not show itself?

The answer to this process of questioning, consistent with the analysis so far performed, and enhancing our insight into the phenomenon of screen, is that this invisibility is itself essential to screen qua screen. The invisibility of screens is not only the invisibility of particular screens but the invisibility of the very essence of screen. This is to say, that screen, in its essence has concealment: they conceal that which is excluded and, more essentially, they conceal what they are for us, as screen. The invisibility we note in screens hides the very essence of the phenomenon screen, which would only be made accessible for us if we consider the meaning of this concealment, that is, the meaning of the invisibility of screens within our own understanding of being - our own being in the world.

\subsubsection{Interpreting Concealed Meanings of Screen}

In this final phase, we need to take into account that which is doing this analysis - we, as beings already in-the-world. The phenomenology presented must now become critical of itself as being presented by us as beings always already in the world. This phenomenological-hermeneutic circle involves a strong methodological claim:

Since we must begin our analysis from within the practices we seek to interpret, our choice of phenomena to interpret is already guided by our traditional understanding of being. Since it deals with what is difficult to notice, this traditional understanding may well have passed over what is crucial, so we cannot take the traditional interpretation at face value. [Dreyfus 1991, p. 36]

By re-analyzing the phenomenological investigation under way, that is, by questioning the realm of human existence as it is humanly experienced, in the light of that which is given in that same phenomenological investigation, and so forth, in circular movements, this phase aims at the discovery of meanings that may not be immediately present to our intuiting, analyzing, and describing. This is what we now aim to do. This will not be easy, as we have to turn the phenomenological intuition "back" on ourselves, as it were. Let us recall the formulation that we initially proffered as the essence of that which is screen: a mediation of our being in the world by presenting relevance. But, what do we mean here by "mediation"? Why "mediate"? And why is "relevance" essential for this concept? 
Our understanding of mediation is revealed within the ontological structure of our own being in the world (Heidegger 1962). Thus, this mediation has the significance of the ways in which we access and give meaning to our own being in the world, that is, to the world where we always and already find ourselves. This mediation appears against the background of understanding that is our being in the world. As a being-in-the-world for which itself is an issue, our being finds itself always thrown from the past and always projected into the future (Heidegger 1962). It is in this thrown-ness, structural to the being we are, that we act in the world, agreeing and disagreeing, choosing and creating meaning - that is, we mediate our own being in the world.

This means that this mediation is already the understanding of our being-in-the world, that which we are. So, having said that, we should ask if this mediation truly mediates. By asking this, we are saying that, whatever this mediation would be, as mediation, it must be agreed on as our manner of being-in-the-world-otherwise it would not mediate (here the concept of agreement emerges again).

Turning to the other elements of our initial formulation of the essence of screen, that is, toward "our being in the world" and "presenting relevance," mediation discloses what is already agreed upon: precisely our being in the world. How does a screen open an agreement of such a kind? Precisely by always and already presenting what is relevant in our flow of involvement, in our particular form-of-life. Thus, what is calling for our attention is not any potential agreement, or anything to be agreed upon as such, but an "already agreement" that is our being-in-the-world - where screens function qua screens.

Because this mediation is that which is already agreed upon, if it is to actually mediate, the concealed path of a screen is not mediation de per si, but rather already agreement. Already agreement is the essence in that it is how it essentially unfolds in the world. Already agreement brings the strands of our analysis together. Screens, in their screen-ness, attract those surrounding them because they are focal points of already agreement. They focus our understanding because they are already agreement on what is relevant, on the ways in which we access relevance, within our understanding in/of the world, in order to be what we are as consultants, train drivers, managers, and so forth.

To conclude, the hidden meaning of screen qua screen - when we consider the kind of investigation we perform as the beings we are in-the-world-reveals itself as already agreement. The essence of screen is already agreement. It is this already agreement that calls our attention, attracts us, makes us look at the screen in its screen-ness, and simultaneously condemns to forgetfulness that which was agreed upon, precisely because it is not an agreement but an already agreement - as such the thinking, the bargaining, the transacting, the negotiating, that typically precede an agreeing are pre-emptively excluded.

This essence as what it is in itself, understood within our being-in-the-world, is the way in which the screen pursues its course, "the way in which it remains through time as what it is" (Heidegger 1977, footnote 3), as already agreement. It is because this concealed meaning of already agreement is that which is most essential for screen, that it does not show itself, but hides itself, as it pursues its way in the world: concealing and spreading already agreement as its essence. 


\subsection{Some Conclusions and Implications}

The essence of screen is already agreement. So what? Why and how is this investigation relevant? In this last section, we briefly address this issue, hoping that the potential of phenomenological investigations of this kind would be evident.

First, we should note that phenomenology is always and already a human activity in the world. We are in the world, and it is as we are in the world that we come to be, to know, or to act in that same world, becoming acquainted and involved with objects and other beings. Our familiarization with an object results "from experiencing it many times, which is a process that performs an unconscious induction all along" (Schmitt 1996, p. 141).

Because empirical objects and empirical events are recognized in accordance to the structure of consciousness - which they presume - they must be logically consistent and must be supported by evident foundational concepts - "matters of fact." As intentional objects, they rely on data from sensory experience and are a source for phenomenological investigation. But what is more, is that at its core the phenomenological way of proceeding is the capacity of consciousness to vary from examples to common-ness, from particulars to general, from existences to essences. This reasoning always occurs in both directions, from essences to actualities and vice-versa. It is precisely this variation that allows consciousness to identify what is shown in each domain.

Thus, the findings of a phenomenological analysis should be projected onto those matters of fact in which it has its sources, both as a coherent possibility and as a new horizon to understand human action in the world. Its results can be applied to specific situations, enhancing its understanding, and clarifying what is at stake. An important possibility of this method, in fact, is the possibility to relate to an "actual world" the investigation developed.

With this in mind, we will briefly present some of the consequences that seem more evident as implications that this investigation has for the empirical world. Unfortunately, we will be brief and can not fully develop and justify these here.

The power of already agreement can, for example, be seen with regard to our general view of television in everyday life. While there are many observations we can make here, we will refer to only one of these. What do we tend to think of people who live, on a permanent basis, without a television in their house? We tend to think of this as strange (possibly even somehow dangerous). Why is this so? Maybe we feel that these people do not share the already agreement - and the relevance implied - that the television is. We often refer to them as "living in another world" for we perceive the television as presenting that which is already agreed as relevant to those engaged in our world. Our analysis provides an explanation for such a view, as Fry (1993, p. 13) puts it, the television has arrived as the context - and those people seem to be out of context.

The power of television to reinforce what is presented just by the presentation itself has important consequences in our daily lives: "all that is important is revealed on television while all that is so revealed on television acquires some authority" (Adams 1993, p. 59). But this power does not belong to the essence of television but rather to the essence of screens, as the following example will show.

The kind of data about us that appears on a screen, at the bank, at the office, at the doctor of medicine, at a public department, is often taken as more valid and trustworthy than ourselves - as many of us have found out to our dismay. That the essence of screen is already agreement indeed helps to explain this: it is because the essence of screen is already agreement that that data is often taken as more valid and trustworthy than 
ourselves. Thus, this primacy of that which is on the screen over that which is not on the screen seems to be an issue that needs to be taken into account while addressing areas such as, among others, human resources management and marketing.

This argument gains a further impact when we consider the questions of change and of management of change. Screens, according to their essence, show already agreement. Thus, it seems reasonable to consider that they allow applications that rely on them to gain an edge of effectiveness - of power - when compared to applications with no screens. If this is so, then either implementation initiatives or contra-implementation initiatives can benefit by acting on screens.

But there is still another aspect important to change management with regard to the simultaneous revealing and concealing nature of screens. Screens, according to their essence, present agreement. However, in revealing agreement, they also conceal potential disagreement or resistance. This potential is always present on the edges of what is revealed/concealed, but always ready to turn screens into displays - to take from screens their self-evident place in the world. Screens in the world are highly fragile phenomena. To establish them may make it very difficult to lose them very easily.

Our analysis also seems relevant for thinking about innovation in a screen filled world. That which deserves to be questioned, it seems to us, is the likelihood that in a screen-intensive environment-that is, in increasingly screen-based "involvement wholes"- the possibilities for innovation would tend to be limited to paths and enigmas, accessible within the already agreement present on the screen. As such, they may hide that which the screen as a setting of context necessarily excludes, thus hiding opportunities for new articulations, new appropriations, and new understandings - which is exactly what innovation is about.

This section only served to highlight some of the possibilities of the empirical application of our phenomenology of the screen qua screen. These are taken as merely very tentative and explorative. They also point to some additional analysis that may be required to further consider the essence of the screen-such as the pages of a journal, newspaper, or magazine as screens. Unfortunately, due to the limits of a paper presentation, we can not pursue all of these possibilities here. Nevertheless, it is hoped that our presentation is sufficient to show the potential of phenomenology to enhance and develop our understanding of the complexity of our involvement in a world increasingly pervaded by screens.

\section{Acknowledgments}

We acknowledge the contributions of colleagues and reviewers for the substantial comments that lead to the improvement of the paper. Fernando M. Ilharco, in contributing to this paper, acknowledges the support of the Portuguese Catholic University, the Calouste Gulbenkian Foundation, and to the Luso-American Foundation for Development for the ongoing support of his Ph.D. research at the London School of Economics. 


\section{References}

ABCnews. Http://archive.abcnews.go.com/sections/world/1997/97_diana.html, December 29, 1999.

Adams, P. "In TV: On 'Nearness', on Heidegger and on Television," in RUA TV? Heidegger and the Televisual, T. Fry (ed.). Sydney: Power Publications, 1993

Biemel, W. "Origin and Development of Husserl's Phenomenology," in Encyclopaedia Britannica (15 ${ }^{\text {th }}$ ed.). Chicago: Encyclopaedia Britannica, 1980, 1995 update.

Boland, R. J. "Information System Use as a Hermeneutic Process," in Information Systems Research: Contemporary Approaches and Emergent Traditions, H-E. Nissen, H. K. Klein, and R. A. Hirschheim (eds.). Amsterdam: NorthHolland, 1991, pp. 439-464.

Boland, R. J. "The In-Formation of Information Systems," in Critical Issues in Information Systems Research, R. J. Boland and R. Hirschheim (eds.). New York: John Wiley \& Sons, 1983.

Boland, R. J. (1985) "Phenomenology: A Preferred Approach to Research on Information Systems" in Research Methods in Information Systems, E. Mumford. R. Hirschheim, G. Fitzgerald, and T. Wood-Harper (eds.). Amsterdam: North-Holland, 1985, pp. 193-201

Boland, R. J. "The Process and Product of System Design," Management Science (28:9), 1978, pp. 887-898.

Boland, R. J., and Day, W.F. "The Experience of System Design: A Hermeneutic of Organizational Action," Scandinavian Journal of Management (5:2), 1989, pp. 87-104.

Borgmann, A. Holding On to Reality: The Nature of Information at the Turn of the Millenium. Chicago: The University of Chicago Press, 1999.

Ciborra, C. U. "De Profundis? Deconstructing the Concept of Strategic Alignment," Department of Informatics University of Oslo, Oslo, Norway, 1997.

Computer Industry Almanac. Http://looksmart.infoplease.com/ipa/A0006115.html, December 23, 1999.

Crystal, D. The Cambrige Encyclopedia of Language, Cambridge, England: Cambridge University Press, 1987.

Detnews. Http://www.detnews.com/1997/diana/9709/05/0098.htm, December 29, 1999.

Dicionário Universal da Lingua Portuguesa. Lisboa, Portugal: Texto Editora, 1999.

Dicionário da Lingua Portuguesa. Porto, Portugal: Porto Editora, 1989.

Dreyfus, H. L. Being-in-the-world: A Commentary on Heidegger's Being and Time, Division I, Cambridge, MA: MIT Press, 1991.

Encyclopaedia Britannica. Http://www.britannica.com, December 23, 1999.

Fry, T. "Switchings" in RUA TV? Heidegger and the Televisual, T. Fry (ed.). Sydney: Power Publications, 1993.

Hammond, M., Howarth, J., and Keat, R. Understanding Phenomenology. Oxford: Blackwell, 1991.

Heidegger, M. Being and Time. Oxford: Blackwell, 1962.

Heidegger, M. “On the Essence of Truth," in Basic Writings. London: Routledge, 1978.

Heidegger, M. The Question Concerning Technology and Other Essays. New York: Harper Torchbooks, 1977.

Hegel, G. W. The Phenomenology of Spirit. Oxford: Clarendon Press, Oxford.

Husserl, E. Cartesian Meditations: An Introduction to Phenomenology. The Hague: Martinus Nijhoff, 1960.

Husserl, E. The Crisis of European Sciences and Transcendental Phenomenology: An Introduction to Phenomenological Philosophy. Evanston, IL: Northwestern University Press, 1970a.

Husserl, E. The Idea of Phenomenology. The Hague: Martinus Nijhoff, 1964a.

Husserl, E. Logical Investigations. New York: Humanities Press, 1970b. 
Husserl, E. Phenomenology of Internal Time Consciousness, by M. Heidegger (ed.) and J. Churchill (trans). Bloomington, IN: Indiana University Press, 1964b.

Husserl, E. "Pure Phenomenology, Its Method and Its Field of Investigation," 1917, reprinted in Husserl: Shorter Works, P. McCormick and F. Elliston (eds.). Notre Dame, IN: University of Notre Dame Press, 1981.

Introna, L. "Information: A Hermeneutic Perspective," in Proceedings First European Conference of Information Systems, Henley on Thames, England, UK. 1993, pp.171-179

Introna, L. Management, Information and Power, London: Macmillan, 1997.

Macann, C. Four Phenomenological Philosophers: Husserl, Heidegger, Sartre, Meleau-Ponty. London: Routledge, 1993.

McCormack, P., and Elliston, F. (eds.). Husserl: Shorter Works. Notre Dame, IN: University of Notre Dame Press, 1981.

Merleau-Ponty, M. Phenomenology of Perception. London: Routledge, 1962.

Michaelis Illustrated Dictionary, Volume I, English-Portuguese. Comp. Melhoramentos de São Paulo, São Paulo, Brasil, 1958.

Minidicionário Verbo-Oxford de Inglês-Português-Inglês. Oxford: Oxford University, and Lisboa, Portugal: Press and Editorial Verbo, 1996.

Nietzsche, F. The Gay Science. New York: Vintage Books, 1974.

Oxford Paperback Dictionary \& Thesaurus, Julia Elliot (ed.). Oxford: Oxford University Press, 1997.

Polt, R. Heidegger: An Introduction. London: UCL Press, 1999.

Schmitt, R. "Phenomenology" in The Encyclopaedia of Philosophy. New York: Macmillan, 1996.

Spiegelberg, H. Doing Phenomenology. The Hague: Martinus Nijhoff Publishers, 1975.

Spiegelberg, H. "Characteristics of Phenomenology," in Encyclopaedia Britannica, $15^{\text {th }}$ ed. Chicago: Encyclopaedia Britannica, 1980, 1995 update.

Spiegelberg, H. The Phenomenological Movement - A Historical Introduction, $3^{\text {rd }}$ ed. Dordrecht: Kluwer Academic Publishers, 1994.

Winograd, T., and Flores, F. Understanding Computers and Cognition. Reading, MA: AddisonWesley, 1987.

Wittgenstein, L. Philosophical Investigations. Oxford: Blackwell, 1967.

WWWebster Dictionary. Http://www.m-w.com, December 17, 1999.

Zuboff, S. In the Age of the Smart Machine. New York: Basic Books, 1988.

\section{About the Authors}

Lucas D. Introna lectures in Information Systems at the London School of Economics and Political Science. He is also Visiting Professor of Information Systems at the University of Pretoria. His research interest is the social dimensions of information technology and its consequences for society. In particular he is concerned with the way information technology transforms and mediates social interaction. He is associate editor of Information Technology \& People and co-editor of Ethics and Information Technology. He is an active member of IFIP WG 8.2, The Society for Philosophy in Contemporary World (SPCW), International Sociological Association WG01 on Sociocybernetics, and a number of other academic and professional societies. His most recent work includes a book, Management, Information and Power (Macmillan, 1997), and various academic papers in journals and conference proceedings on a variety of topics such as the phenomenology of cyberspace, theories of information, information 
technology and ethics, autopoiesis and social systems, and virtual organizations. He holds degrees in management, information systems and philosophy. Lucas can be reached by e-mail at 1.introna@lse.ac.uk.

Fernando M. Ilharco is a Ph.D. student at London School of Economics and Political Science where he is developing a phenomenological investigation into information technology, strategy and the relationships between these two phenomena. From 1993 until 1997, when he started his doctoral studies, he lectured Information Systems at the Portuguese Catholic University, Lisbon, Portugal. In the academic year 1998/99, he taught at LSE, London. For some years now he has been responsible for a weekly column in the leading Portuguese daily newspaper Público where he comments on the political and social implications of IT. He holds a Licenciatura in Law, and an MBA. Fernando can be reached by e-mail at f.ilharco@lse.ac.uk. 